\title{
Toxicology
}

\section{The safety of ethanol infusions for the treatment of methanol or ethylene glycol intoxication: an observational study}

\author{
Mary Kate Wedge, BSc Pharm, ACPR*; Sabrina Natarajan, BSc Pharm, ACPR ${ }^{\dagger}$; \\ Christel Johanson, BSc Pharm, ACPR ${ }^{\dagger}$; Rakesh Patel, MD, MSc, PharmD ${ }^{\ddagger \S}$; Salmaan Kanji, BSc \\ Pharm, PharmD ${ }^{\dagger \S \|}$
}

\section{ABSTRACT}

Background: Methanol or ethylene glycol ingestion may result in significant morbidity or death without prompt treatment. Despite traditional and widespread use of intravenous ethanol as an antidote, its safety is not well described. An evaluation of the safety and ease of titrating ethanol infusions is necessary given the availability of an alternative antidote.

Objective: To evaluate the safety and ease of titrating ethanol infusions for the treatment of methanol or ethylene glycol ingestion.

Methods: We reviewed the hospital records of adults treated with ethanol at The Ottawa Hospital for methanol or ethylene glycol ingestion over a 9-year period. Using a standardized case report form, a single reviewer identified prespecified adverse events that developed after the start of ethanol therapy and classified dose adjustments during ethanol therapy as appropriate or inappropriate based on a priori criteria.

Results: Forty-nine cases of methanol or ethylene glycol ingestion treated with ethanol were included in the analysis, of which 45 underwent hemodialysis, 38 were admitted to the intensive care unit, and 4 died. At least one adverse event was identified in 45 (92\%) cases, including 35 (71\%) with agitation requiring chemical or physical restraints and 10 (20\%) with a depressed level of consciousness treated with intubation. The median number of ethanol concentration measurements per treatment course was 6 (range 0-24), of which only $27 \%$ were within the target range of 22 to $30 \mathrm{mmol} / \mathrm{L}$ and $47 \%$ were below. When measured concentrations were outside the target, the adjustment in ethanol dosing (or lack thereof) was deemed inappropriate $59 \%$ of the time, including $69 \%$ of the time during hemodialysis.

Conclusion: Based on actual practice in a large academic centre, adverse events occur frequently with intravenous ethanol infusions, and ethanol titration is inefficient. The safety profile and therapeutic drug monitoring considerations for ethanol should be considered when choosing an antidote for methanol or ethylene glycol ingestion.

\section{RÉSUMÉ}

Contexte: L'ingestion de méthanol ou d'éthylène glycol, sans traitement rapide, peut causer des troubles importants, voire la mort. Bien que l'administration d'éthanol par voie intraveineuse comme antidote soit une pratique courante, établie depuis longtemps, on n'en connaît pas bien I'innocuité. Compte tenu de l'existence d'un antidote de rechange, une évaluation de l'innocuité et de la facilité d'adaptation posologique des perfusions d'éthanol s'impose.

Objectif: L'étude visait à évaluer l'innocuité et la facilité d'adaptation posologique des perfusions d'éthanol dans le traitement de l'ingestion de méthanol ou d'éthylène glycol.

Méthodes: Nous avons passé en revue les dossiers médicaux d'adultes traités par l'éthanol, à l'Hôpital d'Ottawa, sur une période de 9 ans, pour l'ingestion de méthanol ou d'éthylène glycol. Un seul examinateur a relevé, à l'aide d'un formulaire normalisé d'exposé de cas, l'apparition d'effets indésirables prédéterminés, après le début du traitement par I'éthanol, et l'adaptation posologique du traitement par I'éthanol a été classée appropriée ou inappropriée, selon des critères préétablis.

Résultats: Quarante-neuf cas d'ingestion de méthanol ou d'éthylène glycol traités par l'éthanol ont été relevés aux fins de I'analyse; 45 patients ont été soumis à I'hémodialyse, 38 ont été admis au service de soins intensifs, et 4 sont morts. Au moins un effet indésirable a été observé dans 45 cas $(92 \%)$, notamment une agitation nécessitant une contention physique ou une contrainte chimique (35 cas; $71 \%$ ) et une altération importante de l'état de conscience traitée par intubation (10 cas; $20 \%$ ). Le nombre médian de mesures du taux d'éthanol par série de traitements s'élevait à 6 (plage:

From the *Department of Pharmacy, Saint John Regional Hospital, Saint John, NB; †Department of Pharmacy, $\neq$ Department of Critical Care Medicine, §Division of General Internal Medicine, and IIThe Ottawa Health Research Institute, The Ottawa Hospital, Ottawa, ON.

Correspondence to: Sabrina Natarajan, Department of Pharmacy, The Ottawa Hospital, General Campus, 501 Smyth Road, Ottawa, ON K1H 8L6; snatarajan@ottawahospital.on.ca.

This article has been peer reviewed. 
0-24); $27 \%$ seulement se trouvaient dans la plage cible de 22 à $30 \mathrm{mmol} / \mathrm{L}$, et $47 \%$ étaient en deçà des valeurs indiquées. Lorsque les mesures du taux se situaient hors de la plage cible, l'adaptation posologique des perfusions d'éthanol (ou le manque d'adaptation) était jugée inappropriée $59 \%$ des fois, dont $69 \%$ en cours d'hémodialyse.

Conclusion: D'après l'examen de la pratique dans un grand centre universitaire, les perfusions d'éthanol donnent souvent lieu à des effets indésirables, et leur adaptation posologique est inefficace. Il faudrait tenir compte de la marge d'innocuité et de la pharmacovigilance thérapeutique de l'éthanol lorsque vient le temps de choisir un antidote dans les cas d'ingestion de méthanol ou d'éthylène glycol.

Keywords: ethanol, ethylene glycol, fomepizole, methanol
Methanol or ethylene glycol ingestion may cause significant morbidity or death unless promptly treated. The primary toxic effects of methanol and ethylene glycol result from their conversion by alcohol dehydrogenase and aldehyde dehydrogenase to toxic metabolites: methanol to formic acid and ethylene glycol to glycolic and oxalic acid. ${ }^{1}$ Toxic effects include metabolic acidosis, cardiovascular instability, visual impairment, and renal failure.,3 Standard treatment for methanol or ethylene glycol ingestion involves inhibition of alcohol dehydrogenase using either ethanol or fomepizole. In addition, hemodialysis may be indicated.

Despite the traditional and widespread use of ethanol for the treatment of methanol and ethylene glycol ingestions, there are logistical and clinical challenges associated with its therapeutic use.,5 Ethanol is administered by continuous intravenous infusion until serum measurements of methanol or ethylene glycol are undetectable, often requiring prolonged administration. The duration of treatment can be decreased by hemodialysis, but the ethanol antidote is also removed. As well, the rate of ethanol elimination varies, making it difficult to achieve and maintain so-called therapeutic serum concentrations in the target range of 22 to $30 \mathrm{mmol} / \mathrm{L}$. These characteristics necessitate frequent serum concentration measurements and dosage adjustments. ${ }^{2-4}$ Furthermore, ethanol infusions are not without adverse events. Inebriation, agitation, combativeness, changes in the level of consciousness, hypotension, tachycardia, hypoglycemia, and phlebitis have been commonly reported with its intravenous use. One Canadian study reported a $57 \%$ incidence of adverse events with ethanol infusion. ${ }^{6}$ Given these risks, intensive monitoring of the patient is required.

Fomepizole is also a competitive alcohol dehydrogenase inhibitor and serves as an alternative antidote. It is typically administered intravenously every 12 hours and does not require serum concentration monitoring. ${ }^{4}$
The recommended dose of fomepizole during dialysis is also straightforward and involves its administration at a uniform dose every 4 hours. ${ }^{7}$ The most common adverse events reported with fomepizole include headache, nausea, dizziness, drowsiness, and an unpleasant taste in the mouth. ${ }^{7}$ Although it appears to offer significant advantages relative to ethanol infusions, the major deterrents to its widespread implementation include high acquisition cost and the absence of published evidence demonstrating superior efficacy. ${ }^{1-3,8}$

Guidelines from the American Academy of Clinical Toxicology state that although both ethanol and fomepizole are effective, fomepizole is the preferred antidote for the treatment of methanol poisoning and has clear advantages over ethanol for the treatment of ethylene glycol poisoning. ${ }^{9,10}$ However, at many Canadian hospitals, ethanol is still commonly used as the antidote. We evaluated the safety of ethanol infusions and the ease of titrating these infusions.

The primary objective of the study was to describe the incidence of adverse events associated with the administration of intravenous ethanol infusions. Secondary objectives included the accuracy and appropriateness of ethanol infusion monitoring, titration of ethanol for the antidotal management of methanol or ethylene glycol ingestions, and describing the clinical outcomes of adult patients treated with ethanol at The Ottawa Hospital.

\section{METHODS}

\section{Study design and setting}

This was a retrospective study of adult patients admitted to The Ottawa Hospital for methanol or ethylene glycol ingestion between December 31, 1999, and January 1, 2009. The Ottawa Hospital is a tertiary care referral centre with hemodialysis capability. Approval for this study was obtained from the hospital Research and Ethics Board. 


\section{Selection of participants}

Hospital records were indentified using International Classification of Diseases, ninth or 10th revision, codes for methanol (980.1, T51.1) or ethylene glycol (980.8, T52.8 "other organic solvents") in any diagnostic field. Identified cases were then cross-referenced by disease and treatment with the hospital's data warehouse. The data warehouse contains information from operational databases including patient registration, pharmacy, and discharge abstract. Patients were included if they were $\geq 16$ years of age, had a documented ingestion of methanol or ethylene glycol, and received ethanol as the sole antidote. A patient could contribute more than one poisoning case to the study provided that each ingestion was a separate admission. Patients were excluded if they received antidotal treatment with ethanol at another institution prior to transfer to our hospital or if they received one or more doses of fomepizole.

\section{Data collection}

A standardized case report form was used by a single reviewer (M.K.W.) to record patient demographics, severity of illness, ethanol dose titration, adverse events, and clinical outcomes. Demographic data included type of toxin ingested, age, gender, date and time of presentation, Glasgow Coma Scale (GCS) score, estimated time of ingestion, highest recorded serum concentration of methanol or ethylene glycol, presence of anion and/or osmolar gap at admission, use of antidotal therapy, time of antidotal therapy initiation and duration, and history of coingestion with other substances. The severity of toxicity was determined using the Poison Severity Score (PSS) on admission. The PSS is a standardized, validated scale that further classifies poison morbidity into categories of none, mild, moderate, severe, or death. ${ }^{11}$ The PSS was assigned according to the most severe symptom recorded prior to antidote treatment.

\section{Definitions}

To evaluate the safety of ethanol infusions, all adverse events during the entire ethanol infusion interval were identified. Adverse events were defined a priori as follows: tachycardia (heart rate $>100$ beats/min); hypotension (low blood pressure requiring vasopressor support); decreased level of consciousness (requiring endotracheal intubation for airway protection); agitation (documented as agitation, delirium, or combativeness requiring physical and/or chemical restraints); seizures (witnessed and documented); vomiting; hypoglycemia (blood glucose concentration $<4 \mathrm{mmol} / \mathrm{L}$ ); and phlebitis (documentation of erythema and/or edema at the intravenous site through which ethanol was infusing). ${ }^{9,10,12}$ These adverse events had to be documented as new occurrences after the start of the ethanol infusion; adverse events beginning prior to the infusion were not included.

Every serum ethanol concentration measured during the ethanol infusion was recorded and classified as being within, above, or below the target range of 22 to $30 \mathrm{mmol} / \mathrm{L}$. Every change in ethanol dosing ordered in response to a concentration outside the target range was deemed to be either appropriate or inappropriate. A dose titration was classified as inappropriate in each of these three instances: absence of a documented ethanol infusion rate change within 2 hours of an ethanol serum measurement outside the target range; absence of a documented increase in the ethanol infusion rate within 1 hour of starting hemodialysis or a decrease within 1 hour of stopping; and more than 6 hours of an ethanol infusion without a serum concentration measurement.

The first 24 hours of ethanol therapy were divided into consecutive 6-hour intervals. Each interval was then classified based on the measured serum ethanol concentrations during the interval as being within, above, or below target concentrations. When more than one concentration was measured, the most extreme value (above or below target) was used to classify the interval. Intervals were also designated as to whether or not they contained inappropriate changes in ethanol dosing, using the above definition of inappropriate dose changes. If the serum concentration measured within the 6-hour interval was within the target range, it was included in the analysis and considered to be appropriate. If no serum concentration was measured during a 6-hour interval or if ethanol had been discontinued, that interval was not included in this analysis. Clinical outcome data included intensive care unit (ICU) admission, hemodialysis during hospital admission, dialysis dependence at discharge, visual disturbances, and survival to discharge. 


\section{Statistical analysis}

Data are presented using measures of central tendency or proportions as appropriate, and associations were analyzed using SPSS version 16.0 (SPSS Inc, Chicago, IL). There was no attempt to adjust for patients who presented more than once during the study interval, and the unit of analysis was each discrete hospital admission.

\section{RESULTS}

Of the 154 cases reviewed, 105 were excluded. The reasons for exclusion were as follows: 59 incorrectly coded, 28 started on the ethanol infusion prior to transfer to The Ottawa Hospital, 12 no antidote administered, 5 treated with fomepizole, and 1 younger than 16 years of age. Forty-nine cases treated with ethanol alone were included in the main analysis.

\section{Characteristics of study participants}

Demographic data are summarized in Table 1 . Ethylene glycol ingestion was twice as common as methanol ingestion. Six patients were treated with ethanol on more than one occasion following ethylene glycol ingestion, including one patient who contributed six cases.

\section{Adverse events}

Most ethanol-treated cases developed at least one documented adverse event after the start of ethanol infusion (Table 2). The most common adverse event was agitation treated with physical or chemical restraints, seen in $71 \%$ of cases. One in five patients were intubated for decreased level of consciousness after the start of ethanol. There were no documented hypoglycemic events during ethanol therapy.

\section{Ethanol infusion characteristics}

Ethanol treatment lasted a median of 21 hours, and serum ethanol concentrations were measured a median of six times per case (Table 3). Only 27\% of measured serum ethanol concentrations were within the target range. Altogether, a serum ethanol concentration outside the target was followed by an inappropriate change in ethanol dosing, or lack

\begin{tabular}{|c|c|}
\hline Characteristic & $\begin{array}{c}\text { Cases of methanol or } \\
\text { ethylene glycol } \\
\text { ingestion ( } n=49)\end{array}$ \\
\hline Age in yr, median (IQR) & $38(25-46)$ \\
\hline Male gender, $n(\%)$ & $24(49)$ \\
\hline GCS score on admission, median (IQR) & $15(8-15)$ \\
\hline \multicolumn{2}{|l|}{ PSS on admission (\%) } \\
\hline $0=$ none & $1(2)$ \\
\hline $1=$ mild & $22(45)$ \\
\hline $2=$ moderate & $8(16)$ \\
\hline $3=$ severe & $18(37)$ \\
\hline 4 = death & $0(0)$ \\
\hline \multicolumn{2}{|l|}{ Toxin type, $n(\%)$} \\
\hline Methanol & $15(31)$ \\
\hline Ethylene glycol & $32(65)$ \\
\hline Both & $2(4)$ \\
\hline \multicolumn{2}{|l|}{$\begin{array}{l}\text { Highest recorded serum concentration } \\
\text { of toxin }(\mathrm{mmol} / \mathrm{L}) \text {, median (IQR) }\end{array}$} \\
\hline Methanol & $23(11-64)$ \\
\hline Ethylene glycol & $21(3-36)$ \\
\hline \multicolumn{2}{|l|}{$\begin{array}{l}\text { Anion and/or osmolal gap on admission, } \\
n(\%)\end{array}$} \\
\hline Anion gap $>10^{*}$ & $27(55)$ \\
\hline Osmolal gap $>10^{\dagger}$ & $41(84)$ \\
\hline Both & $25(51)$ \\
\hline $\begin{array}{l}\text { Presentation delay between exposure } \\
\text { and arrival (h), median (IQR) }\end{array}$ & $3(2-5)$ \\
\hline $\begin{array}{l}\text { Heart rate }>100 \text { beats/min pre-ethanol, } \\
n(\%)\end{array}$ & $20(41)$ \\
\hline Vasopressors pre-ethanol, $n(\%)$ & $2(4)$ \\
\hline Intubation pre-ethanol, $n(\%)$ & $15(31)$ \\
\hline $\begin{array}{l}\text { Pre-existing dialysis-dependent renal } \\
\text { failure, } n(\%)\end{array}$ & $0(0)$ \\
\hline $\begin{array}{l}\text { Presentation delay between exposure and } \\
\text { ethanol treatment (h), median (IQR) }\end{array}$ & $5(3-5)$ \\
\hline \multicolumn{2}{|l|}{$\begin{array}{l}\text { Coingestants (a case may have }>1 \\
\text { coingestant), } n(\%)\end{array}$} \\
\hline Pharmaceutical (includes illicit drugs) & $11(22)$ \\
\hline $\begin{array}{l}\text { Nonpharmaceutical (ie, household or } \\
\text { chemical product) }\end{array}$ & $6(12)$ \\
\hline \multicolumn{2}{|c|}{ 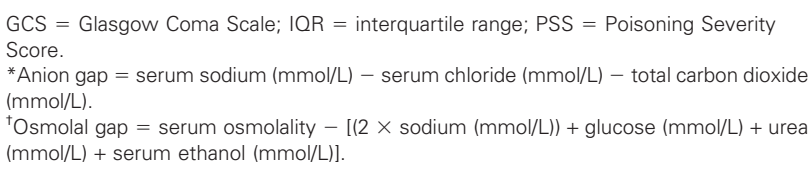 } \\
\hline
\end{tabular}

thereof, $59 \%$ of the time. Almost all cases (92\%) were treated with hemodialysis, but there was a failure to either increase ethanol at the start of hemodialysis or to decrease it at the end in $69 \%$ of the hemodialysis sessions.

The association between the occurrence of adverse events and having a serum ethanol concentration within the target range during a given 6-hour block 


\begin{tabular}{|c|c|}
\hline Adverse event & $\begin{array}{l}\text { Cases of methanol or ethylene } \\
\text { glycol ingestion }(n=49), n(\%)\end{array}$ \\
\hline Any adverse event & $45(92)$ \\
\hline $\begin{array}{l}\text { Tachycardia (heart rate }> \\
100 \text { beats/min) }\end{array}$ & $16(33)$ \\
\hline $\begin{array}{l}\text { Hypotension requiring } \\
\text { vasopressor support }\end{array}$ & $9(18)$ \\
\hline $\begin{array}{l}\text { Decreased level of } \\
\text { consciousness requiring } \\
\text { intubation }\end{array}$ & $10(20)$ \\
\hline $\begin{array}{l}\text { Agitation requiring chemical } \\
\text { or physical restraints }\end{array}$ & $35(71)$ \\
\hline Witnessed seizures & $3(6)$ \\
\hline Vomiting & $11(22)$ \\
\hline $\begin{array}{l}\text { Hypoglycemia (blood glucose } \\
<4 \mathrm{mmol} / \mathrm{L} \text { ) }\end{array}$ & $0(0)$ \\
\hline Phlebitis & $5(10)$ \\
\hline
\end{tabular}

of therapy is in Table 4. Overall, cases were more likely to experience an adverse event during a time interval with ethanol concentrations outside of target (crude odds ratio $2.2 ; 95 \%$ CI $1.1-4.5$ ). The presence of inappropriate ethanol dosing adjustments during any given 6-hour interval was less strongly associated with concurrent adverse events during that interval (odds ratio 1.7 ; $95 \%$ CI $0.83-3.4)$.

\section{Clinical outcomes}

In most cases, the patient was admitted to the ICU and received hemodialysis (Table 5). Only 2 of 17 methanol cases had a fundoscopic examination documented in the medical record, and 1 had visual impairment at discharge. Of the 34 cases in which the patient ingested ethylene glycol, 3 were dependent on hemodialysis at discharge. Overall survival to hospital discharge was $92 \%$.

\section{DISCUSSION}

Based on our hospital's 9-year experience with ethanol for methanol and ethylene glycol ingestion, we found that ethanol was not only difficult to titrate but was also frequently associated with adverse events. Given the availability of an alternative, effective antidote, the risk of adverse events associated with ethanol infusions must be considered when choosing an antidote for methanol and ethylene glycol ingestion.

The incidence of adverse events found in this study was greater than that previously reported in a recent multicentre Canadian study. ${ }^{6}$ Our study may have attributed some adverse events to ethanol that were due to other causes. However, the study by Lepik and

\begin{tabular}{|c|c|}
\hline Ethanol infusion characteristic & $\begin{array}{l}\text { Cases of methanol or ethylene } \\
\text { glycol ingestion }(n=49)\end{array}$ \\
\hline Duration of ethanol infusion (hours), mean (range) & $21(0.5-119)$ \\
\hline Serum concentration measurements per patient, mean (range) & $6(0-24)$ \\
\hline Serum concentration measurements per consecutive 6-hour infusion interval, mean (range) & $1.5(0-5)$ \\
\hline Concurrent hemodialysis, $n(\%)$ & $45(92)$ \\
\hline Therapeutic drug monitoring & $\begin{array}{l}\text { Total ethanol serum concentration } \\
\text { measurements }(n=371), n(\%)\end{array}$ \\
\hline Ethanol concentrations within target range & $102(27)$ \\
\hline Ethanol concentrations above target range & $93(25)$ \\
\hline Ethanol concentrations below target range & $176(47)$ \\
\hline Inappropriate change in dose in response to nontherapeutic serum concentration, $n=269$ & $159(59)$ \\
\hline$>6$ hours of ethanol infusion without therapeutic drug monitoring, $n=223$ & $25(11)$ \\
\hline Dose adjustment for hemodialysis & $\begin{array}{c}\text { Cases with concurrent } \\
\text { hemodialysis }(n=45), n(\%)\end{array}$ \\
\hline Inappropriate change in ethanol dose at start of hemodialysis & $26(58)$ \\
\hline Inappropriate change in ethanol dose at end of hemodialysis & $20(44)$ \\
\hline Either of above & $31(69)$ \\
\hline
\end{tabular}




\begin{tabular}{|c|c|c|}
\hline & $\begin{array}{c}\text { Any adverse } \\
\text { event }(n=143) \\
n(\%)\end{array}$ & $\begin{array}{c}\text { No adverse } \\
\text { event }(n=43), \\
n(\%)\end{array}$ \\
\hline \multicolumn{3}{|c|}{$\begin{array}{l}\text { Most extreme serum ethanol } \\
\text { concentration, } \mathrm{mmol} / \mathrm{L}\end{array}$} \\
\hline $22-30$ & $40(28)$ & $20(47)$ \\
\hline$>30$ & $31(22)$ & $5(12)$ \\
\hline$<22$ & $72(50)$ & $18(42)$ \\
\hline \multicolumn{3}{|l|}{ Change in ethanol dose } \\
\hline Appropriate change & $72(50)$ & $27(63)$ \\
\hline Inappropriate change & $71(50)$ & $16(37)$ \\
\hline
\end{tabular}

colleagues examined a greater variety of adverse events compared to our study. ${ }^{6}$

Central nervous system toxicity characterized by agitation, decreased loss of consciousness, and seizures accounted for the most adverse events. Hypoglycemia was not identified, similar to previous reports. ${ }^{1,6}$ Although hypoglycemia is a commonly cited potential consequence of intravenous ethanol infusions, especially in children, we did not identify any instances, perhaps because ethanol is usually prepared in a dextrose solution for administration and perhaps because we excluded children. ${ }^{4,6}$ Despite frequent ethanol serum concentration monitoring, ethanol concentrations were difficult to maintain in the target range. Only two patients had an ethanol serum concentration consistently within the target range throughout their entire course of therapy. Inappropriate dose titrations, particularly inappropriate responses to nontherapeutic serum concentrations and a lack of titration when starting or stopping hemodialysis, were also frequent. Although our

Table 5. Clinical outcomes

\begin{tabular}{|c|c|}
\hline Outcome & $\begin{array}{l}\text { Cases of methanol or ethylene } \\
\text { glycol ingestion }(n=49)\end{array}$ \\
\hline ICU admission, $n(\%)$ & $38(78)$ \\
\hline Hemodialysis, $n(\%)$ & $45(92)$ \\
\hline $\begin{array}{l}\text { Dialysis dependent at } \\
\text { discharge, } n(\%)\end{array}$ & $3(6)$ \\
\hline Discharge home from ED, $n(\%)$ & $0(0)$ \\
\hline $\begin{array}{l}\text { Hospital LOS (d), median } \\
\text { (range) }\end{array}$ & $8(1-73)$ \\
\hline $\begin{array}{l}\text { Survival to hospital discharge, } \\
n(\%)\end{array}$ & $45(92)$ \\
\hline
\end{tabular}

analysis suggests that so-called therapeutic concentrations might prevent adverse events, achieving such concentrations can be a challenge. Of note, no standardized approach to ethanol titration exists at our institution. ${ }^{1,8}$

The limitations of this study reflect its retrospective nature and reliance on hospital chart data. We could not measure the effect of agitated or combative patients on workplace safety and resource use, including nursing workload. Antidote selection could impact patient and health care worker safety, as well as the intensity of monitoring. ${ }^{\circ}$

This study did not compare ethanol and fomepizole. It is likely that the risk benefit profile favours fomepizole based on the prevalence of adverse events alone. Future pharmacoeconomic studies should include the cost of adverse events and of therapeutic drug monitoring. ${ }^{13}$

\section{CONCLUSIONS}

Adverse events are common with intravenous ethanol infusions. Current practice for dose titration is inaccurate and inefficient in achieving and maintaining target serum ethanol concentrations. The risk of adverse events associated with ethanol infusions should always be considered when choosing an antidote for methanol or ethylene glycol.

Competing interests: None declared.

\section{REFERENCES}

1. Lister D, Tierney M, Dickinson G. Effectiveness of IV ethanol therapy combined with hemodialysis in the treatment of methanol and ethylene glycol poisoning. Can 7 Hosp Pharm 2005;58:42-7.

2. Brent J, McMartin K, Phillips S, et al. Fomepizole for the treatment of ethylene glycol poisoning. N Engl 7 Med 1999; 340:832-8, doi:10.1056/NEJM199903183401102.

3. Brent J, McMartin K, Phillips S, et al. Fomepizole for the treatment of methanol poisoning. $N$ Engl 7 Med 2001;344: 424-9, doi:10.1056/NEJM200102083440605.

4. Morris M, Bedard M, Massicotte A, et al. The Ottawa Hospital: parenteral drug therapy manual. Ottawa: Ottawa Hospital: 2008.

5. Brent J. Antidotes and alcohols: has fomepizole made ethanol an obsolete therapy? Int $7 \mathrm{Med}$ Toxicol. 1998. Available at: http://www.ijmt.net/ijmt/1_1/1_1_2.html (accessed July 23, 2010).

6. Lepik K, Levy A, Sobolev B, et al. Adverse drug events associated with the antidotes for methanol and ethylene glycol poisoning: a comparison of ethanol and fomepizole. 
Ann Emerg Med 2009;53:439-50, doi:10.1016/j.annemergmed.2008.05.008.

7. Jazz Pharmaceuticals. Antizol (fomepizole) injection product monograph. Available at: http://antizol.info/monograph.htm (accessed July 23, 2010).

8. Green R. The management of severe toxic alcohol ingestions at a tertiary care center after the introduction of fomepizole. $A m \mathcal{F}$ Emerg Med 2007;25:799-803, doi:10.1016/j.ajem.2007.01.017.

9. Barceloux DG, Krenzelok EP, Olsen K, et al. American Academy of Clinical Toxicology practice guidelines on the treatment of ethylene glycol poisoning. Clin Toxicol 1999;37: 537-60, doi:10.1081/CLT-100102445.
10. Barceloux DG, Bond GR, Krenzelok EP, et al. American Academy of Clinical Toxicology practice guidelines on the treatment of methanol poisoning. Clin Toxicol 2002;40:41546, doi:10.1081/CLT-120006745.

11. Persson H, Sjoberg K, Haines J, et al. Poisoning severity score-grading of acute poisoning. 7 Toxicol Clin Toxicol 1998;36:205-13, doi:10.3109/15563659809028940.

12. Sweetman S, editor. Martindale: the complete drug reference. 36th ed. London: Pharmaceutical Press; 2009.

13. Brent J. Fomepizole for ethylene glycol and methanol poisoning. N Engl 7 Med 2009;360:2216-23, doi:10.1056/ NEJMct0806112.

\section{Division of Emergency Medicine, Department of Medicine and Family Medicine, McMaster University ACADEMIC EMERGENCY MEDICINE CLINICAL EDUCATOR}

The Division of Emergency Medicine, Faculty of Health Sciences at McMaster University invites applicants for an Academic Emergency Physician to join the Division of Emergency Medicine as the Coordinator of Emergency Medicine Undergraduate Medical Education. The Academic rank will commensurate with the candidate's qualifications and experience.

The Division of Emergency Medicine supports a clinical clerkship rotation of one month for 209 medical students in Hamilton and dis tributed campuses of Niagara and Kitchener-Waterloo. The Undergraduate Co-ordinator is a member of the Clinical Clerkship Committee, the lead person for enhancing curriculum and teaching program in Emergency Medicine, collaborate with the distributed campuses, and oversee the clinical placements. Elective students in Emergency Medicine are also coordinated through the Division. A full time administrative assistant supports this position. The successful candidate will have strong communication and collaborative skills.

Applicants will have completed specialty training in Emergency Medicine. A Masters of Education and/or experience in Undergraduate Medical Education would be a definite asset.

Clinical duties will include membership in the Emergency Department of Hamilton Health Sciences or St. Joseph's Healthcare Hamilton. Full participation in all of the appropriate departmental and divisional educational activities is required.

The successful candidate will be a member of the Division of Emergency Medicine and be expected to contribute to the academic mission of the School of Medicine, Faculty of Health Sciences and Division. This is a Clinician Educator position and the successful candidate should have significant contributions in undergraduate and/or postgraduate education.
Applicants should be certified or eligible for certification by the Royal College of Physicians and Surgeons of Canada or College of Family Practice Canada and must be licensed or eligible for licensure in the Province of Ontario.

Applications must include up-to-date curriculum vitae, description of training and research/educational experience as well as the names and addresses of three professional referees. Applications must be received by October $19,2012$.

Applications should be sent to:

Dr. Margaret Ackerman

c/o Teresa Vallera

Division of Emergency Medicine

McMaster Clinics Second Floor

Hamilton General Hospital

237 Barton Street E.

Hamilton, Ontario L8L 2X2

vallera@mcmaster. ca

All qualified applicants are encouraged to apply. However, Canadian citizens and permanent residents will be considered first for these positions. McMaster University is strongly committed to employment equity within its community, and to recruiting a diverse faculty and stafr. The University encourages applications from all qualified candidates, including women, members of visible minonties, Aboriginal peoples, member of sexual minonities and persons with disabilities. 